\title{
INFLUENCE DE L'INTENSITÉ DU PARASITISME PAR STRONGYLOIDES RATTI SUR LA CORTICOSTÉRONÉMIE DU RAT
}

\author{
par J. BAILENGER, J. B. CHANRAUD et M. GUY*
}

RÉSUMÉ. L'hypercorticostéronémie, qui traduit la réaction des rats à la migration tissulaire des larves de Strongyloides ratti, dépend de l'intensité de la contamination. Elle se ne produit pas lorsque celle-ci est faible ; mais, à partir d'un certain seuil, la valeur et la durée de l'hypercorticostéronémie augmentent parallèlement à l'intensité de l'infestation.

\section{Influence of the degree of infestation by Strongyloides ratti on corticostero- nemia in the Rat.}

SUMMARY. The hypercorticosteronemia which occurs in the rat as a reaction to tissue migration of Strongyloides ratti larvae is proportional to the degree of infestation once this infestation increases beyond a certain point. Below that point, no reaction occurs.

Lors de précédents travaux (1974) nous avons montré que la pénétration cutanée des larves de Strongyloides ratti, dans l'organisme des rats, déclenche une hypercorticostéronémie temporaire, qui atteint son maximum au bout de 48 heures.

Ce travail a pour but de préciser s'il existe une relation entre l'intensité de la réaction cortico-surrénale et l'intensité de l'infestation.

\section{Matériel et méthodes}

Les rats de souche wistar, de sexe mâle et pathogen-free, pèsent $180 \mathrm{~g}$ au début de l'expérience. On les réparti en 6 groupes de $8:$ l'un est infesté par 1000 larves, deux par 3500 larves et deux par 15000 larves; un lot n'est pas infesté.

Pour contaminer les rats on les maintient individuellement, pendant 50 minutes, au contact de $90 \mathrm{ml}$ d'eau renfermant le nombre voulu de larves.

Les prélèvements sanguins en vue du dosage de la corticostérone plasmatique sont toujours effectués à 9 heures; la corticostéronémie est dosée par la méthode

\footnotetext{
* Laboratoire de Zoologie et Biologie animale, U.E.R. Pharmacie, Université Bordeaux II Place de la Victoire, F 33076 Bordeaux
} 
fluorimétrique de De Moor selon les modalités que nous avons précédemment décrites (1974). Chaque dosage est effectué sur un échantillon de plasma constitué pars de volumes égaux du plasma de chaque animal d'un même lot ; le résultat obtenu correspond donc à une valeur moyenne pour les animaux de ce lot.

Pour chaque intensité de contamination, un dosage est effectué 48 heures après la pénétration des larves. Dans le cas des infestations les plus fortes (3 500 et 15000 larves) un nouveau dosage est réalisé 24 heures plus tard. Pour de telles infestations la constitution de 2 lots, permet de faire les prélèvements successifs sur des animaux différents afin d'éviter les conséquences, sur la corticostéronémie, des agressions provoquées par cette intervention.

Afin de s'assurer du pouvoir infestant des larves, on contrôle le parasitisme qu'elles ont déterminé en numérant les œufs et les larves présents dans les selles des rats.

\section{Résultats}

Quarante huit heures après la pénétration transcutanée des larves, l'hypercorticostéronémie, en $\mu \mathrm{g}$ pour $100 \mathrm{ml}$, s'élève à $30,4 \mathrm{chez}$ les animaux infestés par 15000 larves et 21,7 pour les rats soumis à l'infestation par 3500 larves. La corticostéronémie des animaux mis au contact de 1000 larves n'a pratiquement pas varié par rapport aux témoins : 4,5 contre 2,6.

Vingt quatre heures plus tard, la corticostéronémie est encore élevée $(13,5 \mu \mathrm{g} /$ $100 \mathrm{ml}$ ) chez les rats soumis à l'infestation la plus forte, par 15000 larves, mais est redevenue normale chez les autres (tableau I).

Tableau I. - Variations de l'hypercorticostéronémie en fonction de l'intensité du parasitisme

\begin{tabular}{ccrrrrrr}
\hline $\begin{array}{c}\text { Temps } \\
\text { (jours) }\end{array}$ & \multicolumn{2}{c}{1000 larves } & \multicolumn{2}{c}{3500 larves } & \multicolumn{2}{c}{15000 larves } & Témoins \\
Après infestation & P* & B** & P* & B** & P* & B** & B** \\
\hline 2 & - & 4,5 & - & 21,7 & - & 30,4 & 2,6 \\
3 & $6 \overline{400}$ & - & 27600 & & 114400 & 13,5 & - \\
6 & 8800 & & 30400 & & 122400 & & \\
7 & 7200 & & 29600 & & 98400 & & \\
9 & 4800 & & 26800 & & 96000 & & \\
10 & 4800 & & 21200 & & 80000 & & \\
13 & 4000 & 18000 & & 58400 & & \\
\hline
\end{tabular}

* P : Nombre d'œufs et de larves par g de selles.

** B : Corticostéronémie $(\mu \mathrm{g} / 100 \mathrm{ml})$. 


\section{Conclusion}

La réaction hypothalamo-hypophyso-corticosurrénale ne se produit pas lors d'infestation faible ; elle n'existe qu'à partir d'un certain seuil et est alors proportionnelle à l'intensité de l'infestation.

\section{BIBLIOGRAPHIE}

Batlenger J., CARcenac F. Répercussions du parasitisme par Strongyloides ratti sur la sécrétion des gluco-corticostéroïdes chez le rat. Int. J. Parasit., 1974, 4, 307-310. 